\title{
Erratum
}

\section{CORRELATION INVESTIGATION BETWEEN CONTACT APPROACH SPEED OF HANDHELD METAL ROD AND DISCHARGE PARAMETERS FROM CHARGED HUMAN BODY ${ }^{1}$}

\author{
Ruan Fangming $^{* *} \quad$ Fujiwara Osamu ${ }^{* * *} \quad$ Gao Yougang* \\ * (Institute of Electromagnetic Compatibility, Beijing University of Posts \& Telecommunications, \\ Beijing 100876, China) \\ ${ }^{* *}$ (School of Physics \& Chemistry, Guizhou Normal University, Guiyang 550001, China) \\ ${ }^{* * *}$ (Graduate School of Engineering, Nagoya Institute of Technology, Gokiso-cho, Showa-ku, \\ Nagoya, 466-8555, Japan)
}

DOI $10.1007 / \mathrm{s} 11767-008-1001-\mathrm{z}$

The original online version of this article (Journal of Electronics (China), Vol. 25, No. 3, May 2008, pp. 384-388; DOI: 10.1007/s11767-006-0282-3) unfortunately contains a mistake. The manuscript information in the footnote was incorrect. The correct information is given below.

${ }^{1}$ Manuscript received date: December 31, 2006; revised date: August 1, 2007.

Communication author: Ruan Fangming, born in 1958, male, Ph.D. candidate, professor. Beijing University of Posts \& Telecommunications, Beijing 100876, China.

Email: ruan200145@yahoo.com. 